\title{
Social Capital and International Migration from Latin America
}

\author{
Douglas S. Massey ${ }^{1}$ and María Aysa-Lastra ${ }^{2}$ \\ ${ }^{1}$ Office of Population Research, Princeton University, Princeton, NJ 08544, USA \\ ${ }^{2}$ Department of Global and Sociocultural Studies, Florida International University, Miami, FL 33199, USA
}

Correspondence should be addressed to Douglas S. Massey, dmassey@princeton.edu

Received 8 June 2010; Revised 15 March 2011; Accepted 18 April 2011

Academic Editor: T. B. Heaton

Copyright ( 2011 D. S. Massey and M. Aysa-Lastra. This is an open access article distributed under the Creative Commons Attribution License, which permits unrestricted use, distribution, and reproduction in any medium, provided the original work is properly cited.

\begin{abstract}
We combine data from the Latin American Migration Project and the Mexican Migration Project to estimate models predicting the likelihood of taking of first and later trips to the United States from five nations: Mexico, the Dominican Republic, Costa Rica, Nicaragua, and Peru. The models test specific hypotheses about the effects of social capital on international migration and how these effects vary with respect to contextual factors. Our findings confirm the ubiquity of migrant networks and the universality of social capital effects throughout Latin America. They also reveal how the sizes of these effects are not uniform across settings. Social capital operates more powerfully on first as opposed to later trips and interacts with the cost of migration. In addition, effects are somewhat different when considering individual social capital (measuring strong ties) and community social capital (measuring weak ties). On first trips, the effect of strong ties in promoting migration increases with distance whereas the effect of weak ties decreases with distance. On later trips, the direction of effects for both individual and community social capital is negative for long distances but positive for short distances.
\end{abstract}

\section{Introduction}

Research over the past two decades has established the centrality of social networks to the process of international migration. As social beings, humans are inevitably enmeshed in webs of strong ties to close friends and relatives and weak ties to more distant relatives, casual acquaintances, and friends of friends. The set of weak and strong ties to people with current or prior migratory experience constitutes a person's migrant network. Whenever an aspiring international migrant has a social tie to someone with prior migratory experience, that connection offers a potentially valuable source of social capital. By drawing on the tie, individuals can mobilize social capital embedded within it to gain access to valuable information, moral support, and material assistance that may reduce, often quite substantially, the costs and risks of international migration. As a result, people who have migrant friends and relatives display a much higher likelihood of migrating compared with those who do not.

The foregoing summary of network effects is consistent with the theory of social capital and has been confirmed in numerous empirical studies (for reviews, see $[1,2]$ ). Although scholars generally agree that migrant networks have strong effects on patterns and processes of migration, this conclusion does not mean that other factors such as human capital, material assets, political conflict, civil violence, and even the distribution of social capital across transit locations are not also important [3-5]. Nonetheless, the existence and importance of network effects have been documented in migratory systems throughout the world.

Few studies have undertaken a direct comparison of the how network ties work across multiple settings. Studies based on data from the Mexican Migration Project have established a variety of findings: that having a social tie to a current or former U.S. migrant dramatically increases the odds of emigration [6-8], that the size of this effect varies with the strength of the tie and the closeness of the relationship [9], that network effects differ by gender [10-13], that the power of network ties to promote migration is a real causal effect and not spurious or attributable to unmeasured heterogeneity $[14,15]$ and that networks and the social capital they produce are fundamental to the cumulative causation of migration $[16,17]$. These studies have been replicated as well in other regions. Curran and colleagues [18] studied the effects of network composition on internal migration in Thailand and concluded that household-based 
migrant networks (strong ties) were more influential than village-level migrant networks (weak ties) in promoting outmigration.

Despite the theoretical and substantive contributions of these studies, the fact remains that most of them are based on just one case-Mexico-and a rather special one at that. No other developing country shares a 2,000 mile border with an advanced industrial nation, is linked to it through a comprehensive free trade agreement, has a century-long history of significant cross-border movement, and has experienced such extensive political and economic penetration from its developed neighbor. As a result, in concluding their comprehensive review of the North American research literature, Massey et al. [1] argued that "far too much of the research is centered in Mexico, which because of its unique relationship to the USA may be unrepresentative of broader patterns and trends."

In order to address the relative lack of comparative research on international migration, Donato et al. [19] undertook a systematic assessment of international migration from a variety of countries in Latin America and the Caribbean, assembling a series of comparable empirical studies based on data taken from both the Latin American Migration Project and the Mexican Migration Project. In terms of social capital, Alvarado and Massey [20] found that the odds of migrating to the United States from Mexico, Costa Rica, and Guatemala were all strongly increased by having a family tie to a U.S. resident. Fussell [21] likewise found that having a parent or sibling with U.S. experience greatly increased the probability of taking a first U.S. trip among residents of Costa Rica, the Dominican Republic, Mexico, Nicaragua, and Puerto Rico. She also found that a rising prevalence of migrants in the community strongly increased the odds of departure, in Costa Rica, Dominican Republic, and Mexico. Takenaka and Pren [22] found that the likelihood of migrating to the United States from Peru was strongly related to migratory prevalence in the community as well as to the existence of ties to migrant family members, a finding replicated by Massey and Riosmena [23] in samples from Mexico, the Dominican Republic, Nicaragua, and Costa Rica.

Although the analysis by Fussell [21] focused specifically on the effects of social capital, the other studies in the Donato et al. generally considered the influence of other variables of theoretical and substantive interest and simply used measures of social capital as controls. The purpose of this paper is twofold. First, we seek to assess the importance of both individual- and community-level measures of social capital as determinants of international migration relative to other forms of capital. Second, we seek to understand intercountry differences in the relative importance of various measures of human and social capital in predicting international migration and to assess how effects differ with respect to the costs of migration.

\section{Social Capital and Migration}

Building in prior work, we specify four indicators of individual social capital and one measure of community social capital. Individual social capital refers to migration-enhanc- ing resources that come from direct, personal, and usually close ties to particular people with migratory experience in the United States. Community social capital refers to resources emanating from weaker ties to U.S. migrants diffused throughout a community — casual friends, acquaintances, distant relatives, and friends of friends who have been to the United States. In a sense, individual social capital refers to strong ties and community social capital to weak ties, and both sets of ties constitute important sources of instrumental value for people contemplating a trip to the United States, as confirmed in quantitative as well as qualitative studies [24].

Community social capital is measured by the migration prevalence ratio-the proportion of persons aged $15+$ in the community who have ever been to the United States by year $t$, developed originally by Massey et al. [16]. With respect to individual social capital, Fussell [21], Takenaka and Pren [22], and Massey and Riosmena [23] found that ties to different migrant relatives had different effects across national settings, so we measure individual social capital using four separate dichotomous indicators: whether one of the subject's parents had migrated by year $t$, whether any siblings had migrated by year $t$, whether the spouse had migrated by year $t$, and whether any of the subject's children had migrated by year $\mathrm{t}$.

Prior work also suggests that the migratory effects of social capital vary by gender within and across countries $[10,12,13,25]$. In order to simplify the analysis and restrict the number of interactions to be modeled statistically, we, therefore, confined our attention to the migratory behavior of male household heads. In addition to varying by gender, prior work also suggests that social capital effects are not uniform across communities (Garip [26]). Individual social capital generally has stronger effects on out-migration in rural than urban areas $[27,28]$, and the mechanisms of cumulative causation likewise operate more powerfully in rural than in urban areas [29]. Cumulative causation also operates more effectively when social capital is equally distributed among members of a community [30] and when the migration in question is unauthorized rather than legal [21]. Here models estimated to predict the likelihood of taking a first U.S. trip are limited to those migrating without legal documents and all models control for community size. We control for the differential access of people to migrant networks by considering multiple indicators of social capital at the individual level.

Our primary interest here concerns interactions between social capital and two factors of theoretical interest that vary systematically across settings. First, we hypothesize that the relative influence of social capital varies depending on a person's prior migratory experience (see $[8,31]$ ). First-time migrants, by definition, have no direct knowledge of the host society and are crucially dependent on assistance from others to lower their costs and risks. Once in the United States, however, migrants begin to accumulate their own information about how to enter the country, look for work, stay out of trouble, and generally navigate U.S. culture and society. Across successive trips, therefore, migrants tend to substitute their own migration-specific human capital for social capital in managing migration. We, thus, expect social 
capital to have stronger effects on the likelihood of making a first trip than on the probability of making additional trips, which we test by estimating separate models for first and later trips.

Second, we hypothesize an interaction between social capital and the difficulty or cost of making the trip. The higher the cost and the more significant the barriers to international movement, the more we expect migrants to rely on social capital to gain entry and find work in a foreign country. Conversely, the lower the cost of international movement, the less necessary and less valuable social capital will be for potential migrants contemplating an international trip. We test this hypothesis by including cost-capital interactions in equations predicting first and later trips, using distance to destination as a proxy for the cost of migration. Given the focus of prior research on Mexico, this interaction has not been well investigated to date.

Combining the MMP and LAMP data sets yields considerable cross-country variation in the costs, risks, and difficulty of migrating to the United States. Although both the MMP and LAMP surveys asked the cost of hiring a border crossing guide and asked respondents to estimate the total costs of making the trip, we found that outside of Mexico, a majority of trips were made without coyotes and that trip costs were unreliably reported and contained much missing data. At the suggestion of reviewers, therefore, we decided to use the distance between sending and destination communities to proxy the cost of migration. For each migrant, we determined the distance in kilometers between the community of origin and the community of destination. For nonmigrants, we computed potential distance as the average distance to destinations reported by migrants from the same community. For example, if half a community's migrants went to Los Angeles and half went to New York, the potential distance for a nonmigrant contemplating a trip to the United States would be the average of the two distances.

\section{Other Forms of Capital}

Whereas scientific interest in social capital is largely a product of the 1980s, interest in the influence of human and financial capital on migration is older. Sjaastad [32] was the first to theorize human migration in terms of human capital, but the canonical formulation of the neoclassical migration model is that of Todaro [33]. In neoclassical economic terms, migrants are hypothesized to move in order to maximize the financial returns to education, training, skills, and abilities by moving from a low-wage to a high-wage (in this case, foreign) labor market. Recent research suggests that different forms of social capital (e.g., strong and weak ties) and different forms of human capital (e.g., a high school diploma versus a GED) play distinctive roles in determining social outcomes [34, 35]. Our research explores how social capital and human capital interact with the costs of migration to determine the likelihood of international migration.

A priori, the direction of the effect of human capital on the odds of migration between any two countries is indeterminate. One first needs to know how the respective rates of return to human capital at origin and destination and the costs of international movement [1]. In highly unequal societies such as those in Latin America, where education is a scarce, even modest levels of schooling are rewarded in domestic labor markets but are rewarded little internationally, producing a negative selection with respect to human capital. Both Taylor [36] and Massey and Espinosa [8], for example, have documented the negative selectivity of Mexican migrants with respect to education (using different data sets). Whatever the nature of the selectivity, however, one thing is clear: the higher the costs and barriers to international movement, the more selected with respect to human capital are those who do choose to migrate. Thus, we hypothesize a significant interaction between the cost of migration and indicators of individual human capital.

In contrast, as already noted, we predict a substitution between social capital and migration-specific human capital, where the latter is defined as the knowledge, experience, and resources acquired by people in the course of migration itself. We test this hypothesis by estimating separate equations to predict departure on first and later trips and include indicators of migration-specific human capital in the latter, hypothesizing that they will absorb a share of the variance formerly accounted for by indicators of individual and community social capital, thus reducing the size of coefficients associated with them. On later trips, we measure migration-specific human capital using three indicators: the number of U.S. trips made by the respondent through year $t$, total U.S. experience accumulated through year $t$, and whether or not residence documents had been acquired by year $\mathrm{t}$. For most international migrants, documents are attained through connections made while in the United States. Although in a few instances migrants leave on a first trip in documented status, this occurs mostly for sons, daughters, and spouses of legal immigrants, and since our models are estimated for male household heads, very few began migrating legally and the effect of documentation thus is not readily estimable in predicting initial U.S. trips, leading us to analyze only undocumented a first trips but to include an indicator of documentation for later trips.

Financial capital also plays a role in neoclassical economic thinking about international migration. Although we cannot measure financial capital per se using MMP and LAMP data, we can measure the ownership of financial assets such as land, housing, and business enterprises, which we label physical capital. Like human capital, the effect of immobile physical assets on out-migration is indeterminate under neoclassical theory. On the one hand, assets can provide income or collateral for loans to finance a trip abroad. On the other hand, if the potential income from assets is significant, it may reduce the attractiveness of international migration. In general, research from around the world finds that migrants come from somewhere in the middle of the wealth distribution - rich enough to be able to finance a trip but poor enough to have unsatisfied ambitions at home [1].

A more recent avenue of economic theorizing, however, views assets in a different way. The new economics of labor migration argues that international migration may not only be undertaken to maximize earnings, but also to over come failures in capital and credit markets [37]. Because these 
markets are nonexistent, poorly functioning, or inefficient in many developing countries, people are unable to finance agricultural production, the purchase of large consumption items (such as housing), or the establishment of a business enterprise.

In terms of the assets considered here, already owning a home indicates the lack of a major motivation for migration (the need to self-finance home acquisition) and is thus hypothesized to be negatively related to the odds of outmigration. Around the world, the most important single use of migrant remittances is the acquisition or improvement of homes [1], and studies in Mexico have generally found home ownership to be negatively related to international migration [8]. In similar fashion, owning a business signifies the lack of a need for investment capital and also provides an additional source of earnings to reduce the net gain from emigration, lending it a negative influence on the probability of international movement.

The same might be said of land, except that land often requires significant ongoing investment to make production profitable in a market economy. During the 1940s, for example, Mexican authorities redistributed land to peasants but did not provide them with financial assistance to undertake production, generating a demand for investment capital that was met by migrating to the United States [6]. To the extent that a similar situation prevails in other Latin American settings - with households owning land but lacking the financial means to make it maximally productive in a market economy-we would expect land ownership to exert a similarly positive effect on the odds of out-migration.

\section{Source of Data}

Cross-national research to date has been limited by the lack of comparable and reliable data for different countries. Fortunately, the Latin American Migration Project (LAMP) was modeled on the Mexican Migration Project (MMP) specifically to address this limitation by compiling equivalent data sets using comparable questionnaires and similar data collection methods across a range of countries in Latin America and the Caribbean. Here, we take advantage of LAMP data to compare the relative importance of network ties in determining first and later trips to the United States from Mexico, the Dominican Republic, Costa Rica, Nicaragua, and Peru.

The MMP began in 1982 and since 1987 has annually surveyed communities throughout Mexico to build a comprehensive data base on documented and undocumented migration to the United States. Its procedures and the resulting data have been well-described in numerous publications (see [38-41]). In brief, each year 4-6 communities ranging in size from small villages to neighborhoods in large metropolitan areas are selected and surveyed using simple random sampling methods. Within each community, a semistructured interview known as an ethnosurvey is applied to gather social, demographic, and economic information about each household and all of its members. A special module collects information on the first and last trips made by each member to the United States, and all household heads and spouses are administered a retrospective questionnaire that compiles a complete history of migration and border-crossing from age 15 (or age of entry into the labor force) onward. MMP questionnaires and a description of the sample and data sets are available from the project's website at http://mmp.opr.princeton.edu/.

Each Mexican community survey is followed a few months later by a survey of out-migrants originating in that community who have settled in the United States and no longer return regularly to be interviewed there. These respondents are located using snowball methods, also known as chain-referral and network-driven sampling methods. Data from the U.S. and Mexican surveys are then cleaned, coded, and assembled into composite files that are representative of the binational population of migrants formed through recurrent processes of migration and settlement in the United States (see Massey and Zenteno [39]) for a demonstration of the data's representativeness).

The LAMP was launched in 1998 as a self-conscious attempt to replicate the design and methods of the Mexican Migration Project. As with the MMP, communities of various sizes are selected and surveyed using semistructured questionnaires and simple random sampling methods, and each sending community sample is followed by a survey of migrants located in U.S. destination areas using snowball sampling techniques. Here, we make use of the surveys that have been carried out in the Dominican Republic, Costa Rica, Nicaragua, and Peru. Preliminary analyses of LAMP data suggest they are valid and accurate and, like the MMP data, yield a valid picture of patterns and process of both documented and undocumented migration to the United States (see [42]).

Whereas the MMP used the exactly the same survey instrument at all field sites, total consistency was not possible in the LAMP. Geographic conditions, patterns of social and economic organization, and variables of interest, such as documentation, border crossing, and land tenure, differ from country to country. As a result, there is no a single "LAMP questionnaire" in the same way that there is a uniform MMP questionnaire. Rather, LAMP investigators developed a "Template questionnaire" that is adapted to each local situation to yield a standard body of data on international migration. As with the MMP, the countryspecific questionnaires, full documentation, and a detailed description of the data are available from the project website at http://mmp.opr.princeton.edu/.

Sampling information for the MMP and LAMP surveys used in this analysis are summarized in Table 1. Given its long history, the sample compiled in Mexico by the MMP is by far the largest and most extensive, containing 128 communities with 21,474 households and 138,711 persons at the time we carried out this research. The average Mexican community was surveyed in 1997 with a sampling fraction of $14.3 \%$ and a refusal rate of $7 \%$. To represent the Caribbean, the Dominican Republic was surveyed in 1999 with a sample size 978 households and 5,913 persons, yielding a sampling fraction of $13 \%$ and a refusal rate of $4 \%$. To represent Central America, Costa Rica and Nicaragua were sampled in 2002 
TABLE 1: Sampling information for surveys conducted in selected countries by the Latin American and Mexican Migration Projects.

\begin{tabular}{|c|c|c|c|c|c|}
\hline Sampling information & Mexico & Dominican Republic & Costa Rica & Nicaragua & Peru \\
\hline \multicolumn{6}{|l|}{ Community samples } \\
\hline Number of communities & 128 & 7 & 7 & 9 & 4 \\
\hline Number households & 20,552 & 904 & 1,391 & 1,598 & 677 \\
\hline Sampling fraction & 14.2 & 13.1 & 22.0 & 19.0 & 11.7 \\
\hline Refusal rate & 7.4 & 4.3 & 3.6 & 4.3 & 38.4 \\
\hline \multicolumn{6}{|l|}{ U.S. samples } \\
\hline Number of households & 922 & 74 & 37 & 65 & 48 \\
\hline Number of persons & 4,930 & 370 & 168 & 303 & 170 \\
\hline \multicolumn{6}{|l|}{ Total sample } \\
\hline Number of households & 21,474 & 978 & 1,428 & 1,789 & 725 \\
\hline Number of persons & 138,711 & 5,913 & 7,414 & 11,168 & 3,742 \\
\hline Average survey year & 1997 & 1999 & 2002 & 2002 & 2003 \\
\hline
\end{tabular}

with respective sampling fractions of $22 \%$ and $19 \%$ and a refusal rate of $4 \%$, yielding corresponding totals of 1,428 and 1,789 households and 7,414 and 11,168 persons.

Only in Peru did LAMP interviewers experience significant problems with respondent cooperation, yielding a rather high refusal rate of $38 \%$. Three of the four communities surveyed were working class areas in metropolitan Lima, where rates of crime and urban violence were high and rising, causing much fear and a palpable reluctance to talk to strangers. Whereas the refusal rate in the one community surveyed outside of Lima was just 11\%, within the metropolitan area itself the rate ranged from $39 \%$ to $48 \%$. Although standard practice in both the MMP and LAMP has been not to offer payments to respondents, in Lima, we made an exception and purchased a basic pocket calculator as a small gift for each household that agreed to participate. The final sample size was 725 households and 3,572 persons, achieved with a sampling fraction of $12 \%$.

In this analysis, we draw upon data compiled from life histories of male household heads to undertake a discretetime event history analysis. Following Massey and Espinosa's [8] study of migration from Mexico, we undertake separate analyses to model the likelihood of taking a first U.S. trip and then move on to model the process of taking an additional trip given that one has already occurred. For the analysis of first trips, we follow each male head year by year from age 15 to the survey date and assess whether the person left for the United States as an undocumented migrant in that year. Undocumented migrants are those who crossed the border without authorization or who entered with a short-term visa and then violated its terms by working or staying too long. Following Massey and Espinosa, we only consider person years lived since 1965 to limit recall error. Each year in which the person did not migrate was coded 0 and the year in which the first trip was taken was coded 1. All person years subsequent to the first trip are excluded to provide a detailed look at the process by which international migration is initiated.

In order to study the process by which migration is perpetuated, we follow each household head year by year following a return from the United States up to the time he leaves on the next trip, coding person years where no trip was taken as 0 and ones where an additional trip was made as 1 and keeping track of the number of prior trips and the accumulated total of U.S. experience. This analysis also includes people migrating in legal status, as a small number of people have been able to acquire documentation by virtue of their prior U.S. experience. This coding is repeated for all intervals between trips up to the survey date, at which point the data are censored. In all analysesfor first as well as subsequent U.S. trips-independent variables are measured in year $t$ and the outcomes (dichotomous indicators of migration) are measured in year $t+1$. With the exception of fixed characteristics such as gender, country, and community of origin, all variables are time varying.

\section{Access to Forms of Capital Across Latin America}

In Table 2, we show mean values of variables used in our analysis of migration to the United States. With the exception of measures of migration-specific human capital, these figures assess the situation of male household heads in the average person year lived prior to the first U.S. trip or the survey date, whichever came first. Reflecting its location and long history of migration to the United States, respondents from Mexico are generally wealthiest in terms of individual social capital (see top panel). Among Mexican heads, 6\% had a migrant parent, $15 \%$ a migrant sibling, $1 \%$ a migrant spouse, and $6 \%$ a migrant child.

However, household heads from the Dominican Republic display only slightly less access to individual social capital, reflecting the intensity of a migration stream that began in the early 1960s when the U.S. ambassador began giving out legal residence documents to politically active Dominicans to get them out of the country and restore order [43]. In the average person year under observation, $4 \%$ of Dominican respondents had a migrant parent, $18 \%$ a migrant sibling, $1 \%$ a migrant spouse, and $5.5 \%$ a migrant child. In the remaining nations, however, access to individual social 
TABLE 2: Variables used in the analysis of first out-migration from five origin contexts in Latin America.

\begin{tabular}{|c|c|c|c|c|c|}
\hline Independent variables & Mexico & Dominican Republic & Nicaragua & Costa Rica & Peru \\
\hline \multicolumn{6}{|l|}{ Forms of capital } \\
\hline \multicolumn{6}{|l|}{ Individual social capital } \\
\hline Parent a U.S. migrant & 0.063 & 0.039 & 0.007 & 0.007 & 0.010 \\
\hline U.S. migrant siblings & 0.147 & 0.177 & 0.083 & 0.081 & 0.149 \\
\hline Spouse a U.S. migrant & 0.010 & 0.011 & 0.006 & 0.005 & 0.001 \\
\hline U.S. migrant children & 0.062 & 0.055 & 0.030 & 0.022 & 0.017 \\
\hline Social capital index & 0.231 & 0.235 & 0.108 & 0.098 & 0.149 \\
\hline \multicolumn{6}{|l|}{ Community social capital } \\
\hline Percent migrants in community & 12.153 & 12.293 & 5.603 & 4.206 & 1.137 \\
\hline \multicolumn{6}{|l|}{ Individual human capital } \\
\hline Education & 5.831 & 7.999 & 7.420 & 8.022 & 12.906 \\
\hline Years of labor force experience & 12.895 & 11.562 & 14.087 & 14.368 & 13.917 \\
\hline Skilled occupation at home & 0.076 & 0.105 & 0.150 & 0.159 & 0.248 \\
\hline Human capital index & 0.366 & 0.404 & 0.470 & 0.492 & 0.638 \\
\hline \multicolumn{6}{|l|}{ Migration-specific human capital* } \\
\hline Number of prior trips & 1.476 & 0.792 & 0.674 & 0.522 & 0.046 \\
\hline Years of prior U.S. experience & 4.777 & 6.441 & 6.740 & 4.322 & 1.855 \\
\hline Documentation attained & 0.134 & 0.409 & 0.161 & 0.070 & 0.053 \\
\hline \multicolumn{6}{|l|}{ Physical capital } \\
\hline Land & 0.139 & 0.102 & 0.065 & 0.114 & 0.030 \\
\hline Home & 0.483 & 0.313 & 0.479 & 0.477 & 0.531 \\
\hline Business & 0.128 & 0.128 & 0.233 & 0.188 & 0.163 \\
\hline \multicolumn{6}{|l|}{ Key control variables } \\
\hline \multicolumn{6}{|l|}{ First versus later trip } \\
\hline Took additional trip & 0.191 & 0.054 & 0.027 & 0.083 & 0.053 \\
\hline \multicolumn{6}{|l|}{ Cost of migration } \\
\hline Distance to U.S. destination & 2201.3 & 1621.2 & 2202.8 & 2960.3 & 4680.1 \\
\hline \multicolumn{6}{|l|}{ Control variables } \\
\hline \multicolumn{6}{|l|}{ Community Size } \\
\hline Metro area & 0.286 & 0.223 & 0.108 & 0.464 & 0.721 \\
\hline Town or city & 0.230 & 0.317 & 0.892 & 0.277 & 0.279 \\
\hline Rural village & 0.485 & 0.460 & 0.000 & 0.259 & 0.000 \\
\hline \multicolumn{6}{|l|}{ Demographic background } \\
\hline Age & 35.416 & 35.816 & 35.555 & 35.690 & 38.491 \\
\hline Married or in union & 0.738 & 0.677 & 0.731 & 0.667 & 0.696 \\
\hline Number of children under 18 & 2.090 & 1.709 & 1.672 & 1.348 & 1.384 \\
\hline \multicolumn{6}{|l|}{ Period } \\
\hline Before 1980 & 0.376 & 0.310 & 0.274 & 0.268 & 0.323 \\
\hline 1980-1989 & 0.302 & 0.284 & 0.265 & 0.269 & 0.261 \\
\hline 1990-1995 & 0.169 & 0.214 & 0.202 & 0.197 & 0.191 \\
\hline After 1996 & 0.120 & 0.157 & 0.226 & 0.234 & 0.193 \\
\hline Person years & 284,751 & 15,754 & 32,544 & 28,994 & 15,009 \\
\hline
\end{tabular}

${ }^{*}$ Defined for those who took at least one trip.

capital drops markedly, reflecting the relative recency of U.S. migration from these settings. In these countries, fewer than $1 \%$ of household heads reported having a migrant parent or spouse, and only $2 \%-3 \%$ had migrant children. The most frequent category for access to social capital was siblings. Around $8 \%-14 \%$ of respondents reported having a sibling who had been to the United States.
Access to community-level social capital-measured by the proportion of U.S. migrants present in the community during the average person year-generally follows the same pattern. In general, the average Mexican and Dominican subjects lived in a place in which $12 \%$ of the surrounding community residents had been to the United States, followed closely by Nicaragua at $6 \%$. The percentage was markedly 
lower in Costa Rica and Peru, with values of $4 \%$ and $1 \%$, respectively.

In general, cross-national patterns with respect to human capital endowments are opposite those observed for social capital. At one extreme are Peruvians, who averaged 13 years of schooling, 14 years of labor force experience, and a quarter of whom held skilled occupations (recall that most of these respondents were from metropolitan Lima). Skilled occupations were those classified as professional, managerial, clerical, or skilled manual. At the other extreme are Mexicans, with a mean education of only 6 years and just $8 \%$ in skilled occupations, though labor force experience was more extensive at 13 years. In between these two extremes are Dominicans, Costa Ricans, and Nicaraguans, who report average educations of 7-8 years, percentages of skilled workers in the range of $10 \%-16 \%$, and an average time in the labor force of around 14 years.

The distribution of physical capital across countries is less consistent. Home ownership is most common in Peru at 53\%, followed by Mexico, Nicaragua, and Costa Rica at around $48 \%$ each, and least common in the Dominican Republic at only $31 \%$. In contrast, land ownership is most frequent in Mexico at 14\%, followed by Costa Rica at $11 \%$, the Dominican Republic at 10\%, Nicaragua at 6\%, and Peru at $3 \%$. Business ownership is most common in Nicaragua, where nearly a quarter owned businesses, followed by Costa Rica at $19 \%$, Peru at $16 \%$, and Mexico and the Dominican Republic at about $13 \%$.

\section{Key Control Variables}

Table 2 also shows certain variables that we propose as key controls in our analysis of social and human capital effects on the likelihood of migration. We first measure whether the trip being predicted is an initial or later departure to the United States. As expected, repeat migration is most common among Mexicans, 19\% of whom took more than one trip, followed by Costa Ricans at $8 \%$, Dominicans and Peruvians at $5 \%$ and Nicaraguans at $3.5 \%$. These figures suggest differential access across countries to migrationspecific human capital, and this is precisely what we find. Among those at risk of taking an additional trip, Mexicans had the largest number of prior trips (1.4 on average), followed by Dominicans (0.79), Nicaraguans (0.68), Costa Ricans (0.52), and Peruvians (0.05). In terms of total U.S. experience, however, Nicaraguans were greatest at 6.7 years and Peruvians least at 1.8 years, with Dominican Republic, Mexico, and Costa Rica in between with 6.4, 4.7 and 4.2 years, respectively. Whereas circular migration is quite common among Mexicans, long-term settlement is characteristic of Costa Ricans and Peruvians.

We also find considerable heterogeneity between countries in terms of access to documentation on later trips. By far the greatest access is enjoyed by Dominicans, who in the early 1960s were granted privileged access to legal status as part of an American plan to defuse political unrest in the wake of the U.S. invasion [44]. This action later yielded a migration stream composed disproportionately of legal migrants [43]. Thus, among Dominicans contemplating an additional U.S. trip, $41 \%$ had legal papers. Nicaraguans were also given privileged access to documents by the Nicaraguan Adjustment and Central American Relief Act because they were fleeing a left-wing regime and their documentation rate is consequently relatively high at $16 \%$, even greater than Mexico's $13 \%$ despite the fact that its migration is much more recent. Lacking either the political impetus of the Dominican Republic and Nicaragua or the long migration history of Mexico, Costa Ricans and Peruvians experience the least access to documentation on later trips, with respective rates of documentation of only $7 \%$ and $5 \%$.

A second key control variable is the cost of migration, which we proxy using the average distance between places of origin and destination. Although Mexico shares a land border with the United States, it does not display the lowest average distance to the United States, a distinction that goes to the Dominican Republic. Both Mexico and the United States are geographically quite large and migrants come from all over Mexico and go to all over the United States (see [45]). For most migrants, moving to the United States does not involve a simple trip across the border but a long journey between distant points such as Puebla and New York, Oaxaca and Chicago or Veracruz and Los Angeles. In contrast, the Dominican Republic is a small, compact country and migrants concentrate disproportionately at one particular point of destination, New York City, which is 1,587 kilometers away, yielding an average distance of just 1,626 kilometers compared with an average distance of 2,203 kilometers for Mexicans.

Nicaragua is also a relatively small country whose migrants concentrate in Miami, which is only 1,020 kilometers distant from Managua, but a secondary node in Los Angeles and significant settlements elsewhere produced a higher average distance of 2,202 kilometers, the same as Mexico. Although Costa Rica is next to Nicaragua and itself a compact country, it sends migrants to a wider variety of U.S. destinations, yielding an average distance of 2,960 kilometers. The most distant migrants obviously come from Peru, which also sends to a variety of U.S. destinations but with particular concentrations in New York and Los Angeles, yielding an average distance of 4,680 kilometers.

\section{Other Control Variables}

Less important theoretically but nonetheless important control in our analyses are community size, demographic background, and period. We control for community size by dividing samples into three categories: rural villages of fewer than 2,500 inhabitants, small towns and cities up to 50,000 inhabitants, and metropolitan areas containing greater than 50,000 inhabitants. In terms of demographic background, we control for age, marital status, and presence of minor children in the household. To measure period we divide person years into four broad categories: before 1980, which corresponds to the final stage of import substitution industrialization in Latin America, 1980-1989, often referred to by Latin Americans as "the lost decade" because of the collapse of import substitution as a development strategy and the widespread decline in real living standards, 
TABLE 3: Effects of different forms of capital on the probability that a male household head from five Latin American societies took a first trip to the United States 1965-survey date.

\begin{tabular}{|c|c|c|c|c|c|}
\hline Independent variables & Mexico & Dominican Republic & Nicaragua & Costa Rica & Peru \\
\hline \multicolumn{6}{|l|}{ Forms of capital } \\
\hline \multicolumn{6}{|l|}{ Individual social capital } \\
\hline Parent a U.S. migrant & $0.580 * * *$ & $1.221^{* *}$ & $1.900 * * *$ & $1.233^{* *}$ & - \\
\hline U.S. migrant siblings & $0.875^{* * *}$ & $1.158^{* * *}$ & $1.538^{* * *}$ & $0.563^{*}$ & 1.015 \\
\hline Wife a U.S. migrant & $0.697 * * *$ & $2.182^{* * *}$ & $1.961^{* * *}$ & $1.535^{* *}$ & - \\
\hline U.S. migrant children & $0.399 * *$ & - & -0.420 & 0.381 & - \\
\hline \multicolumn{6}{|l|}{ Community social capital } \\
\hline Percent U.S. migrants & $0.031^{* * *}$ & 0.012 & $0.055^{* *}$ & $0.145^{* * *}$ & 0.290 \\
\hline \multicolumn{6}{|l|}{ Individual human capital } \\
\hline Education & $-0.035^{* * *}$ & 0.044 & $0.105^{* * *}$ & 0.034 & -0.082 \\
\hline Years of LF experience & $0.019 * * *$ & 0.012 & 0.012 & $0.062^{*}$ & -0.011 \\
\hline Skilled occupation & $-0.647^{* * *}$ & 0.309 & $-0.780^{*}$ & -0.470 & 0.620 \\
\hline \multicolumn{6}{|l|}{ Physical capital } \\
\hline Land & -0.030 & 0.668 & -0.312 & -0.172 & - \\
\hline Home & $-0.143^{* *}$ & -0.328 & 0.108 & -0.191 & -1.028 \\
\hline Business & $-0.446^{* * *}$ & -0.242 & 0.269 & 0.145 & - \\
\hline \multicolumn{6}{|l|}{ Control variables } \\
\hline \multicolumn{6}{|l|}{ Community size } \\
\hline Metro area & $-0.540^{* * *}$ & -0.010 & $-0.638+$ & $-2.307^{* * *}$ & - \\
\hline \multicolumn{6}{|l|}{ Demographic background } \\
\hline Age & $-0.045^{* * *}$ & 0.160 & 0.101 & $-0.165^{*}$ & 0.158 \\
\hline Age squared & $-0.0007^{* * *}$ & $-0.003+$ & $-0.0015+$ & 0.001 & -0.001 \\
\hline Married or in union & -0.066 & -0.005 & 0.451 & $0.685^{* *}$ & -0.058 \\
\hline No. children $<18$ & $0.0332 * *$ & -0.029 & $-0.146+$ & -0.007 & -0.668 \\
\hline \multicolumn{6}{|l|}{ Period } \\
\hline$<1980$ & - & - & - & - & - \\
\hline 1980-1989 & 0.012 & 0.425 & $0.882 * *$ & $0.452+$ & -0.554 \\
\hline 1990-1995 & -0.029 & -0.242 & -0.403 & -0.33 & 0.113 \\
\hline $1996+$ & $0.409^{* * *}$ & -0.967 & -0.699 & $-1.343^{* *}$ & -0.930 \\
\hline Intercept & $-2.866^{* * *}$ & $-8.635^{* * *}$ & $-9.323 * * *$ & $-2.989 * *$ & $-10.65^{* *}$ \\
\hline Likelihood ratio & $4,939.86^{* * *}$ & $68.27^{* * *}$ & $175.86^{* * *}$ & $271.32 * * *$ & 9.31 \\
\hline Somer's D & 0.596 & 0.593 & 0.568 & 0.677 & 0.139 \\
\hline Person years observed & 284,751 & 15,754 & 32,544 & 28,994 & 15,009 \\
\hline
\end{tabular}

1990-1995, during which neoliberal forms were being introduced to many countries, and 1996 to the survey date, when the consequences of neoliberal structural adjustment policies were becoming evident. Mean values for all control variables are given in Table 2 .

\section{Social Capital and First Migration: Country-Specific Effects}

Table 3 presents a discrete time event history analysis undertaken to measure the influence of different forms of capital on the probability of leaving on a first trip to the United States from the five countries under consideration. Individuals were followed year-by-year from their entry into the labor force up to the first trip or survey date, whichever came first. We predicted whether or not they undertook a first U.S. trip in year $t+1$ from independent variables defined in year $t$ using a logit regression model, which yields a discrete time event history analysis. In assessing results, we generally focus on the effects of social capital, with ancillary attention paid to human and less to physical capital.

The top panel shows estimated effects for our four indicators of individual social capital on the likelihood of taking a first trip the United States. These estimates offer the first comparative analysis of social capital's effects across a broad sample of Latin American nations using comparable methods and data. In general, findings provide strong support for the theory of social capital. Given the small sample size and the tiny share of subjects having a parent, wife or child who had been to the United States in Peru, we only estimate the effect of a migrant sibling for that country. Among the remaining 15 coefficients, 13 are significant 
and positive, indicating that a social tie to someone with migratory experience increases the odds of migrating to the Untied States. Among the four non-significant effects, two are in the expected direction and quite large, suggesting that with larger samples they might also have attained statistical significance. (We conducted this analysis in two ways, once as shown in the table and also by counting up the number of ties to relatives with U.S. experience regardless of family relationship. Goodness of fit statistics indicated greater variance explained by models considering the family relationships separately than those using counts of ties, so we focused interpretation on the former.)

Thus strong, positive social capital effects on initial outmigration are by no means limited to Mexico but appear to be general throughout Latin America. Considering only the significant coefficients, as one moves from left to right in the table - that is from fewer to greater costs of migrationthe absolute size of the social capital coefficients generally increases, with a few exceptions. Moreover, Mexico is the only country sharing a land border with the United States and it generally displays the smallest country-specific social capital coefficients. Broadly speaking, then, these results are consistent with the hypothesis that social capital is more important when the barriers to movement are high.

In addition and also consistent with prior research, our indicator of community social capital (the prevalence of migrants in the community) is strong and significant in three cases: Mexico, Nicaragua, and Costa Rica. The insignificant coefficients in the Dominican Republic and Peru probably reflect the relatively urban nature of the samples, as Fussell and Massey [29] have demonstrated that even in Mexico community social capital is not significant in urban areas. In Peru the prevalence of U.S. migration is also very low and displays little variance, mitigating against finding a significant effect.

Consistent with the proposition that human capital effects are indeterminate under neoclassical theory, we encounter considerable diversity in the size and direction of effects for the various indicators of human capital. The effect of education is negative and significant in Mexico, positive and significant in Nicaragua and Costa Rica, and insignificant in the Dominican Republic and Peru. Greater labor force experience positively predicts migration in Mexico and in Costa Rica but is not significantly related to migration in the other countries. The only variable to show relatively consistent effects is occupational skill. In three of the five cases, the effect is negative and in two the effect is statistically significant (though only marginally in the case of Costa Rica).

Finally, with respect to the effect of physical capital on first migration, we find very few significant effects. In no country does land ownership predict out-migration to the United States, and only in Mexico does business ownership do so. Home ownership is significantly related to the odds of taking a first U.S. trip only in Mexico. The overall effects are all negative, which is more consistent with predictions derived from the new economics of labor migration than from neoclassical economics. That is, households already owning homes and businesses do not need to self-finance their acquisition through international migration.

\section{Social Capital and First Migration: General Processes}

The foregoing results from five nations generally provide strong and consistent support for the centrality of migrant networks and the importance of social capital in international migration. Being connected to someone with prior U.S. experience, and residing in a community where many people have already been to the United States, appear universally to increase the odds of undertaking a first U.S. trip. We did, however, observe certain irregularities among the coefficients, which in some cases did not conform to hypotheses. We now address these divergences by pooling the data for all countries to come up with a set of stable estimates reflecting general processes of first migration, and then use these data to estimate theoretically expected interactions between the cost of migration and social capital.

Table 4 pools the data across countries and estimates two models. The one shown in the left-hand columns includes indicators of individual social capital, community social capital, individual human capital, and physical capital plus controls for community size, demographic background, period, and country of origin, with Mexico serving as the reference. The right-hand columns estimates the same equation but adding the natural $\log$ of distance to the U.S. as another control to serve a proxy for the costs of migration.

The left-hand columns confirm that throughout Latin America, leaving on a first trip to the United States is strongly predicted by having a tie to someone with prior migratory experience though the strength of the effect varies with the nature of the tie. In general, having a migrant sibling is most powerful in predicting out-migration to the United States, with an estimated effect of 0.901 , followed by having a migrant wife and having migrant parent with respective effects of 0.774 and 0.584 . These effects are significantly smaller than the effect of having a migrant sibling $(P<$ $.05)$. Having a child with U.S. experience is least powerful in predicting initial migration to the United States, and the effect of 0.304 is significantly different from the effects of having migrant siblings. The effect of community social capital on first migration is also positive and robustly significant. Other things equal, coming from a community with a higher share of U.S. migrants strongly increases the odds that someone will decide to undertake a first trip.

In terms of human capital, education and occupational skill negatively predict initial out-migration to the United States whereas years of labor force experience positively predict it. As a general rule, therefore, migrants from Latin America are negatively selected with respect to education and skill. Those most likely to leave for the United States are those with the least skill and education but the most work experience. Without documents, education and skill are unlikely to be rewarded in the U.S. labor market, whereas a willingness to work hard, particularly in onerous jobs that American natives avoid, is more likely to be rewarded north of the border. Owning a home and business likewise negatively predict initial out-migration, suggesting a general pattern of negative selectivity with respect to physical capital. 
TABLE 4: Effects of different forms of capital on the probability that a male household head from five Latin American societies took a first trip to the United.

\begin{tabular}{|c|c|c|c|c|}
\hline \multirow{2}{*}{ Independent variables } & \multicolumn{2}{|c|}{ No controls for distance } & \multicolumn{2}{|c|}{ Controlling for distance } \\
\hline & $B$ & SE & $B$ & SE \\
\hline \multicolumn{5}{|l|}{ Forms of capital } \\
\hline \multicolumn{5}{|l|}{ Individual social capital } \\
\hline Parent a U.S. migrant & $0.584^{*}$ & 0.045 & $0.594^{* * *}$ & 0.046 \\
\hline U.S. migrant siblings & $0.901^{* * *}$ & 0.038 & $0.898^{* * *}$ & 0.038 \\
\hline Wife a U.S. migrant & $0.774^{* * *}$ & 0.096 & $0.744^{* * *}$ & 0.097 \\
\hline U.S. migrant children & $0.304^{*}$ & 0.120 & $0.308^{*}$ & 0.121 \\
\hline \multicolumn{5}{|l|}{ Community social capital } \\
\hline Prop. U.S. migrants in community & $0.030 * * *$ & 0.001 & $0.030^{* * *}$ & 0.001 \\
\hline \multicolumn{5}{|l|}{ Individual human capital } \\
\hline Education & $-0.026^{* * *}$ & 0.004 & $-0.027^{* * *}$ & 0.005 \\
\hline Years of labor force experience & $0.021^{* * *}$ & 0.005 & $0.022^{* * *}$ & 0.005 \\
\hline Skilled occupation at home & $-0.582^{* * *}$ & 0.085 & $-0.603^{* * *}$ & 0.087 \\
\hline \multicolumn{5}{|l|}{ Physical capital } \\
\hline Land & -0.038 & 0.060 & -0.044 & 0.061 \\
\hline Home & $-0.136^{* *}$ & 0.043 & $-0.151^{* * *}$ & 0.043 \\
\hline Business & $-0.355^{* * *}$ & 0.065 & $-0.365^{* * *}$ & 0.066 \\
\hline \multicolumn{5}{|l|}{ Key control } \\
\hline \multicolumn{5}{|l|}{ Cost of migration } \\
\hline Natural log of distance to US & - & - & $-0.392^{* * *}$ & 0.052 \\
\hline \multicolumn{5}{|l|}{ Other controls } \\
\hline \multicolumn{5}{|l|}{ Community size } \\
\hline Metro area & $-0.569^{* * *}$ & 0.055 & $-0.692^{* * *}$ & 0.058 \\
\hline Town or city & - & - & - & - \\
\hline Rural village & 0.051 & 0.037 & 0.057 & 0.037 \\
\hline \multicolumn{5}{|l|}{ Country of origin } \\
\hline Mexico & - & - & - & - \\
\hline Dominican republic & $-1.336^{* * *}$ & 0.144 & $-1.610^{* * *}$ & 0.158 \\
\hline Costa rica & $-0.306^{* * *}$ & 0.087 & $-0.229^{*}$ & 0.094 \\
\hline Nicaragua & $-0.997^{* * *}$ & 0.108 & $-1.051^{* * *}$ & 0.112 \\
\hline Peru & $-2.296^{* * *}$ & 0.410 & $-1.919^{* * *}$ & 0.413 \\
\hline \multicolumn{5}{|l|}{ Demographic background } \\
\hline Age & $-0.052^{* * *}$ & 0.012 & -0.053 & 0.013 \\
\hline Age squared & $-0.001^{* *}$ & 0.000 & $-0.0005^{* *}$ & 0.000 \\
\hline Married or in consensual union & -0.016 & 0.046 & -0.006 & 0.046 \\
\hline Number of children under 18 & $0.022^{* * *}$ & 0.011 & $0.026^{*}$ & 0.011 \\
\hline \multicolumn{5}{|l|}{ Period } \\
\hline Before 1980 & - & - & - & - \\
\hline 1980-1989 & 0.036 & 0.040 & 0.026 & 0.040 \\
\hline $1990-1995$ & -0.033 & 0.055 & -0.050 & 0.056 \\
\hline After 1996 & $0.297^{* * *}$ & 0.067 & $0.304^{* * *}$ & 0.068 \\
\hline Intercept & $-2.926^{* * *}$ & 0.184 & 0.100 & 0.447 \\
\hline Likelihood ratio & $6,004.88^{* * *}$ & & $6,017.00^{* * *}$ & \\
\hline Somer's D & 0.626 & & 0.629 & \\
\hline Person years & 377,052 & & 376,957 & \\
\hline
\end{tabular}


The demographic controls behave as one might expect. Controlling for labor force experience, age has a negative effect on the odds of taking a first U.S. trip, one that accelerates as the years advance. Although being married or in a union is positively related to the likelihood of departure, the effects are not statistically significant; however, the presence of children under age 18 is positively related and statistically significant. The only period coefficient that is significant is that corresponding the post-1996 period when the effects of neoliberal restructuring reached their apogee. The coefficients associated with country dummy variables are strongly negative and highly significant. Given that the reference category is Mexico, this result implies that sharing a land border with the United States yields a higher likelihood of first migration apart from other variables in the model.

The right-hand columns show the effect of the foregoing variables once the log of distance is included to control for the relative cost of migration. As expected, distance has a strong, negative, and highly significant effect on the odds of taking a first trip to the United States. The farther one's community is from U.S. destinations, the less the likelihood of leaving on a first trip. Despite this strong effect, however, none of the other coefficients change in any meaningful way as a result of controlling for distance. The fact that the country coefficients do not change, in particular, suggests that sharing a land border with the United States yields a higher likelihood of first migration irrespective of the actual distances involved.

In addition, the fact that the effects of individual and community social capital do not change suggests that having ties to U.S. migrants increases the likelihood of departure at all distances. The latter finding, however, does not preclude significant interactions with distance and, as hypothesized above, we do not expect the migratory effects of social capital to be same irrespective of cost. On the contrary, we hypothesize that the effects of both individual and community social capital will become more important as the costs of international movement rise, a hypothesis we test in the next section.

\section{Interactive Models of Social Capital and First Migration}

Table 5 shows the results of an equation estimated to capture these interactions. As before, we pooled the data from all countries and include distance to measure the cost of migration, interacting it with indicators of human and social capital. In order to avoid a proliferation of interaction terms, we consolidated the separate indicators of individual social and human capital into a summary index. Specifically, we weighted each indicator with its corresponding coefficient from Table 4 and added them together to created summated ratings scale of individual human capital. In this way, each component in the resulting index is weighted to reflect its relative importance in predicting out-migration. We repeated the same exercise to create a summated ratings scale of individual human capital. Means for these indices are shown in Table 2.
The left-hand equation estimates the model with main effects only. As we would expect, individual and community social capital continue to have very strong, positive, and robust effects on the likelihood of leaving for the United States. Both coefficients are more than 30 times their standard errors. The human capital index has a strong and significant negative effect on initial out-migration. The righthand equation includes terms for the hypothesized interactions. The inclusion of interaction terms does not change the effects of other variables in the model. In particular, Mexico continues to have a much higher probability of initial outmigration than other countries, suggesting once again that sharing a land border with the United States increases the odds of migration apart from social capital, distance, or any interactions between them.

All of the interaction terms are statistically significant, meaning that the effects of human and social capital are not uniform but vary by distance from points of destination. Inclusion of the interaction term between the individual social capital index and distance produces a positive interaction and turns the main effect from positive to negative. Inclusion of the interaction term between community-level social capital and distance also maintains the main effect positive but the interaction itself is negative. In the case of the distance-human capital interaction, the main effect remains negative and increases while the interaction term is positive.

It is difficult to see how the interaction plays out just looking at the coefficients. In order to explore the theoretical and practical implications of the interactions we generate predicted probabilities of taking a first U.S. trip. Specifically, we let the variables being interacted run from their minima to maxima while holding all other variables constant at their means and applying the coefficients estimated in Table 5 . The results of this exercise are plotted in Figure 1 through Figure 4. In order to establish a baseline for interpretation, Figure 1 graphs the main effects for individual social capital, community social capital, and human capital using the model shown in the left-hand columns of Table 5. Since testing our hypothesis requires the inclusion of interaction terms we present estimated coefficients instead of oddsratios for all our models to provide the reader with uniform estimators (see [46]).

Over the observed range of each variable, we see that individual social capital is most powerful in predicting the likelihood of departing on a first trip to the United States, raising the probability from near zero at its minimum to 0.040 at its maximum. The effect of community social capital is more modest, with the probability going from zero to 0.018 as the share of migrants goes from minimum to maximum. Human capital has a small negative effect on the likelihood of initiating U.S. migration, reducing the probability of movement from 0.01 at its minimum to near zero at its maximum. None of these predictions, however, takes into account the significant interactions we detected in the model shown on the right-hand side of Table 5.

Figure 2 illustrates what happens when the interaction between individual social capital and distance is taken into account. Here, we generate predicted probabilities of first migration by letting the individual social capital index runs 
TABLE 5: Event history models of the probability that a male household head from five Latin American societies took a first trip to the United States 1965-survey date.

\begin{tabular}{|c|c|c|c|c|}
\hline \multirow{2}{*}{ Independent variables } & \multicolumn{2}{|c|}{ Main effects only } & \multicolumn{2}{|c|}{ With interactions } \\
\hline & $B$ & SE & $B$ & SE \\
\hline \multicolumn{5}{|l|}{ Forms of capital } \\
\hline \multicolumn{5}{|l|}{ Individual social capital } \\
\hline Social capital index & $0.948^{* * *}$ & 0.031 & -0.428 & 0.744 \\
\hline \multicolumn{5}{|l|}{ Community social capital } \\
\hline Prop. U.S. migrants in community & $0.030 * * *$ & 0.001 & $0.187^{* * *}$ & 0.040 \\
\hline \multicolumn{5}{|l|}{ Individual human capital } \\
\hline Human capital index & $-0.799 * * *$ & 0.082 & $-10.302^{* * *}$ & 1.866 \\
\hline \multicolumn{5}{|l|}{ Physical capital } \\
\hline Land & -0.049 & 0.061 & -0.055 & 0.061 \\
\hline Home & $-0.120^{* *}$ & 0.043 & $-0.115^{* *}$ & 0.043 \\
\hline Business & $-0.358^{* * *}$ & 0.066 & $-0.371^{* * *}$ & 0.066 \\
\hline \multicolumn{5}{|l|}{ Key control } \\
\hline \multicolumn{5}{|l|}{ Cost of migration } \\
\hline Natural log of distance & $-0.383^{* * *}$ & 0.053 & $-0.514^{* * *}$ & 0.103 \\
\hline \multicolumn{5}{|l|}{ Interactions } \\
\hline Individual social capital $\times \log$ distance & - & - & $0.181+$ & 0.097 \\
\hline Prop. migrants $\times \log$ distance & - & - & $-0.020^{* * *}$ & 0.005 \\
\hline Individual human capital $\times \log$ distance & 一 & 一 & $1.238^{* * *}$ & 0.242 \\
\hline \multicolumn{5}{|l|}{ Other controls } \\
\hline \multicolumn{5}{|l|}{ Community size } \\
\hline Metro area & $-0.713^{* * *}$ & 0.058 & $-0.704^{* * *}$ & 0.058 \\
\hline Town or city & - & - & - & - \\
\hline Rural village & $0.072+$ & 0.037 & $0.066+$ & 0.037 \\
\hline \multicolumn{5}{|l|}{ Country of origin } \\
\hline Mexico & - & - & - & - \\
\hline Dominican republic & $-1.655^{* * *}$ & 0.157 & $-1.585^{* * *}$ & 0.159 \\
\hline Costa Rica & $-0.232^{*}$ & 0.093 & $-0.312^{* *}$ & 0.095 \\
\hline Nicaragua & $-1.077^{* * *}$ & 0.111 & $-1.069^{* * *}$ & 0.112 \\
\hline Peru & $-2.007 * * *$ & 0.412 & $-2.353^{* * *}$ & 0.418 \\
\hline \multicolumn{5}{|l|}{ Demographic background } \\
\hline Age & -0.004 & 0.011 & -0.003 & 0.012 \\
\hline Age squared & $-0.001^{* * *}$ & 0.000 & $-0.001^{* * *}$ & 0.000 \\
\hline Married or in consensual union & 0.0168 & 0.046 & 0.018 & 0.046 \\
\hline Number of children under 18 & $0.027^{*}$ & 0.011 & $0.026^{*}$ & 0.011 \\
\hline \multicolumn{5}{|l|}{ Period } \\
\hline Before 1980 & - & - & - & - \\
\hline 1980-1989 & $0.088^{*}$ & 0.039 & $0.098^{*}$ & 0.039 \\
\hline 1990-1995 & 0.057 & 0.052 & 0.072 & 0.052 \\
\hline After 1996 & $0.448^{* * *}$ & 0.062 & $0.468^{* * *}$ & 0.062 \\
\hline Intercept & $-0.752+$ & 0.440 & 0.239 & 0.804 \\
\hline Likelihood ratio & $5,917.27^{* * *}$ & & & \\
\hline Somer's D & 0.626 & & 0.627 & \\
\hline Person years & 376,957 & & 376,957 & \\
\hline
\end{tabular}

from its minimum to maximum at seven different levels of distance: the minimum observed distance, minus two standard deviations below the mean, minus one standard deviation, precisely at the mean, plus one standard deviation, plus two standard deviations, and at the maximum. At the minimum distance — say a community in a Mexican border state-access to individual social capital has virtually no effect and the curve is flat. In this case, destinations are so close and accessible that having ties to people with migrant experience makes little difference in predicting the odds 


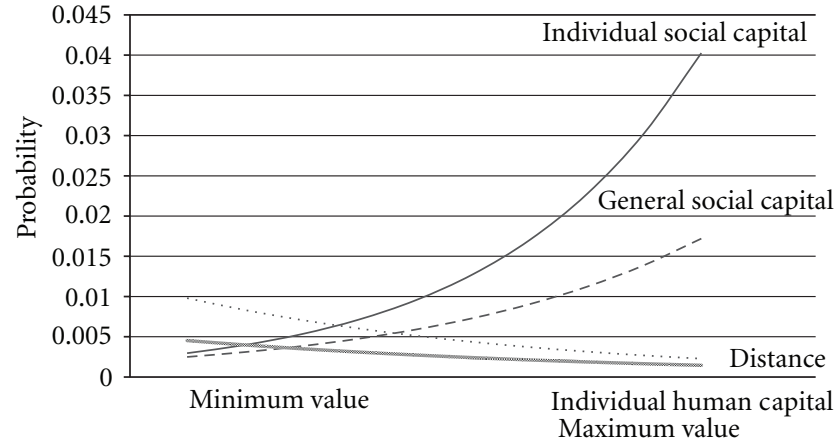

Figure 1: Main effects of individual social capital, general social capital, individual human capital, and distance on the probability of taking a first US trip.

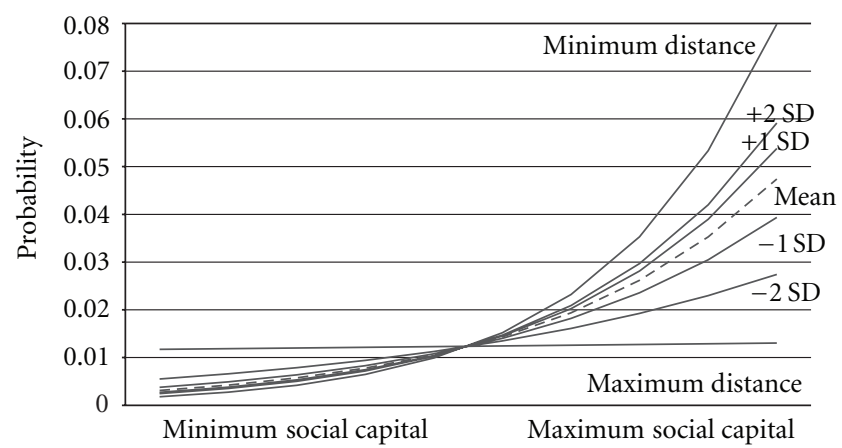

Figure 2: Interactive effect of individual social capital and distance on the probability of taking a first U.S. trip.

of movement. As distance increases, however, the effect of individual social capital becomes steadily more pronounced and at the maximum distance, the swing is from 0.002 to 0.08 as social capital increases from minimum to maximum. As hypothesized, therefore, access to individual social capital in the form of direct ties to people with migrant experience becomes increasingly important in predicting migration as the costs of migration rise.

In contrast, as shown in Figure 3, the interaction between community social capital and distance works in a different way. In this case, as distance increases the effect of social capital diminishes. At the minimum distance, shifting the share of migrants in the community from its minimum to maximum raises the probability of migration from 0 to 0.89 , an effect so large we did not plot it. At two standard deviations below the mean, increasing the share of migrants in the community from its minimum to maximum raises the probability from 0 to 0.2 -still a large effect (see Figure 3 ). At one standard deviation above the mean distance the swing is only from 0 to 0.044 and at the mean distance it goes from 0 to just 0.018 . If we assume that community social capital - the proportion of people in the community with prior U.S. experience-indicates access to weak ties whereas individual social capital (direct ties to specific people with U.S. experience) indicates access to strong ties, then Figure 3 implies that weak ties are primarily important when the

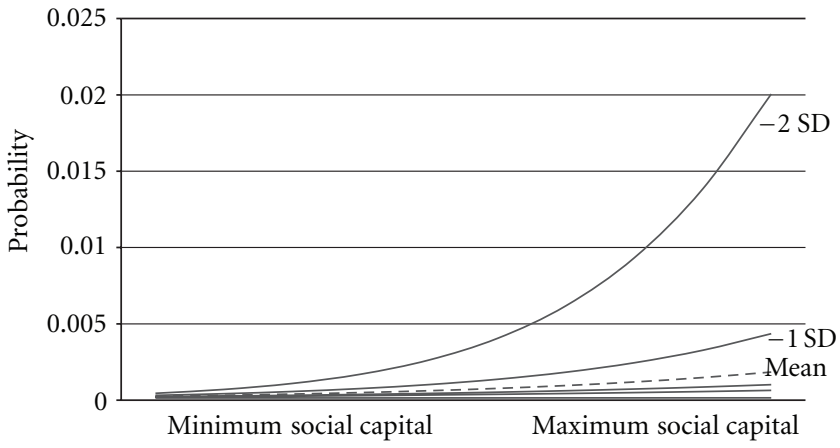

FIGURE 3: Interactive effect of general social capital and distance on the probability of taking a first U.S. trip.

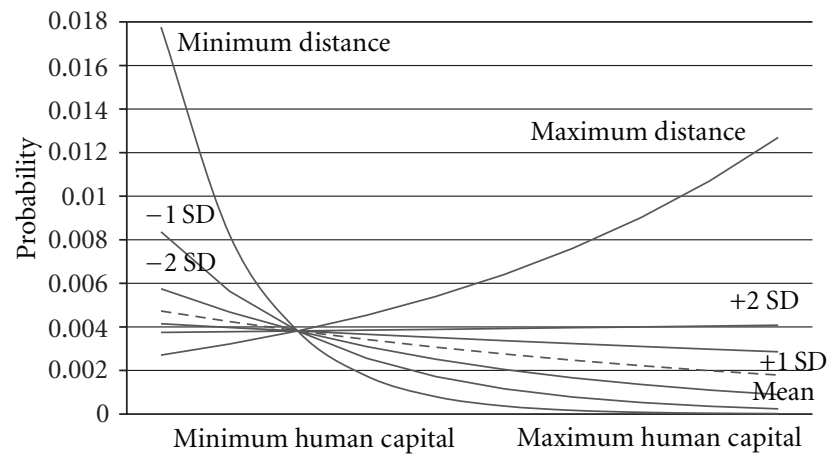

Figure 4: Interactive effect of individual human capital and distance on probability of taking a first U.S. trip.

cost of migration is low. In contrast, strong ties are most important when the cost of migration is high. In other words, weak ties become less important as the cost of migration rises, even though they are very powerful when the costs of migration are small, which explains why the effect of community social capital is so strong in Mexico compared with other countries (see Table 2).

The interaction between distance and human capital is even more complex, with the direction of the effect changing completely as distance moves from minimum to maximum as shown in Figure 4. When distance is at its minimum, reflecting the lowest cost of migration, the effect of increasing human capital is negative going from about 0.018 at the minimum to zero at the maximum. The negative effect of human capital moderates, however, as distance increases and at two standard deviations the curve is relatively flat. At maximum distance, the relationship between human capital and migration actually becomes positive, raising the probability of departure from zero to 0.0124 , explaining why in Peru migrants are positively selected by education whereas in Mexico they are negatively selected.

\section{The Process of Repeat Migration}

People who migrate to the United States return to their communities of origin qualitatively changed. They have 
gained knowledge about the process of migration and valuable experience in U.S. markets. Knowledge and skills gained in the course of migration yields migration-specific human capital, and research done in Mexico has shown it promotes the taking of additional U.S. trips. Once someone has lived and worked in the United States and returned home, the probability is high that they will leave againmuch higher than the likelihood of taking a first trip [6]. In Mexico, the odds of taking an additional U.S. trip generally rise with each trip taken, a process that yields a pattern of recurrent circular migration $[47,48]$. In addition, the likelihood of another trip also increases with the cumulative amount of time spent in the United States [8].

In Table 6, we show results for two models estimated to predict the likelihood of taking an additional U.S. trip, adding to the independent variables considered before our three indicators migration-specific human capital: number of prior trips, cumulative U.S. experience, and possession of documents. The left-hand columns show a model estimated for main effects only, whereas the right-hand columns show a model that includes capital-distance interactions. As expected, indicators of migration-specific human capital are all highly significant in predicting repeat migration to the United States.

Considering the main effects in the left-hand columns, we see that as in Mexico, the odds of taking another trip rise with each trip taken and are, not surprisingly, dramatically increased by the possession of legal documents. Unlike in Mexico, however, the effect of cumulative U.S. experience is strong and negative. Recurrent migration is relatively common in Mexico, of course, and migrants often accumulate large amounts of U.S. experience across multiple trips, so both trips and experience end up positively predicting the taking of additional trips. In other countries, however, recurrent migration is uncommon, and migrants more frequently adopt a settled strategy, remaining in the United States for long durations before returning home. The general pattern, therefore, is that U.S. experience negatively predicts the odds of going again. Mexico is the exception and not the rule. In general, a large number of prior trips indicates that the migrant-whether Mexican or not-has established a pattern of recurrent movement back and forth and is likely to migrate again, but a long duration of time spent in the U.S. suggests that the migrant has established a pattern of settled migration and is less likely to go again.

As hypothesized, social capital is less powerful in predicting later as opposed to initial trips, which can be seen by comparing the main effect models in Tables 5 and 6. Moving from first to later trips, the coefficient for community social capital drops from 0.030 to 0.012 and the coefficient for individual social capital not only drops in value but changes sign, going from 0.948 to -0.098 . Once people have been to the United States, whether they go again has much more to do with their own experiences in the U.S. than with their social connections to other migrants.

As with initial trips, however, the right-hand columns indicate that capital-cost interactions are significant though in this case all the main effects are positive and the interaction terms are all negative. What this pattern means is illustrated

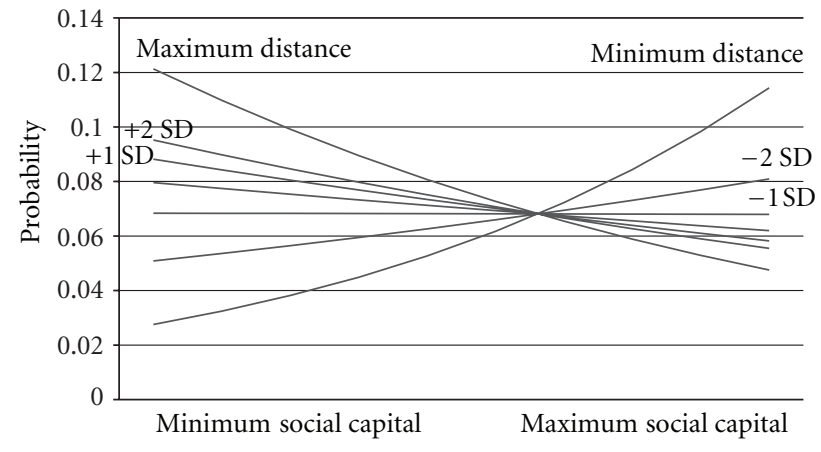

FIGURE 5: Interactive effect of individual social capital and distance on probability of taking an additional U.S. trip.

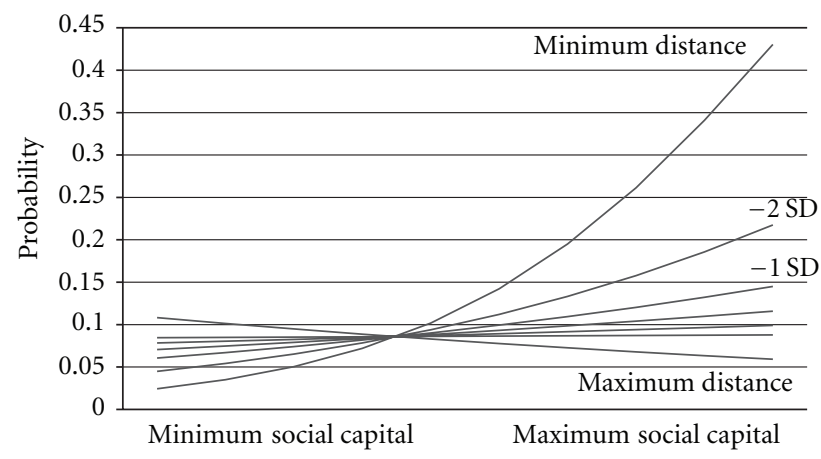

FIGURE 6: Interactive effect of general social capital and distance on the probability of taking an additional U.S. trip.

in Figure 5, which plots the effect of individual social capital on the likelihood of repeat migration at different levels of distance. When distances are small and the cost of migration presumably low, the relationship between individual social capital and high parity migration is positive: more social capital increases the odds of taking another trip. At the minimum observed distance, for example, the likelihood of taking an additional trip rise from just under 0.03 with minimum individual social capital to nearly 0.12 at maximum social capital. In contrast, when distance is great and the cost of migration high, the relationship between individual social capital and repeat migration is negative: more social capital reduces the odds of leaving again. At the maximum observed distance, as individual social capital moves from its minimum to maximum, the probability of taking another trip falls from 0.12 to just under 0.05 . In other words, when one is far away, having other migrants in the family apparently reduces the odds of moving again, possibly because family members act as substitutes rather than complements to an individual's movement in the face of high costs.

Figure 6 plots the interaction between distance and community social capital, and here, just as in the model for first trips, we encounter the opposite pattern: at minimum distance (low cost) community social capital has a small negative effect on the odds of taking another grip, whereas at maximum distance (high cost) community social capital 
TABLE 6: Event history models of the probability that a male household head from five Latin American societies took an additional trip to the United States 1965-survey date.

\begin{tabular}{|c|c|c|c|c|}
\hline \multirow{2}{*}{ Independent variables } & \multicolumn{2}{|c|}{ Main effects only } & \multicolumn{2}{|c|}{ With interactions } \\
\hline & $B$ & SE & $B$ & SE \\
\hline \multicolumn{5}{|l|}{ Forms of capital } \\
\hline \multicolumn{5}{|l|}{ Individual social capital } \\
\hline Social capital index & $-0.098^{* * *}$ & 0.018 & $1.581^{* * *}$ & 0.377 \\
\hline \multicolumn{5}{|l|}{ Community social capital } \\
\hline Prop. U.S. migrants in community & $0.012^{* * *}$ & 0.001 & $0.104^{* * *}$ & 0.028 \\
\hline \multicolumn{5}{|l|}{ Individual human capital } \\
\hline Human capital index & $-0.006^{* * *}$ & 0.001 & $0.073^{*}$ & 0.035 \\
\hline \multicolumn{5}{|l|}{ Migration specific human capital } \\
\hline Prior U.S. experience & $-0.176^{* * *}$ & 0.004 & $-0.175^{* * *}$ & 0.004 \\
\hline Number of prior U.S. trips & $0.662 * * *$ & 0.008 & $0.663^{* * *}$ & 0.008 \\
\hline Documented & $0.552^{* * *}$ & 0.040 & $0.547^{* * *}$ & 0.041 \\
\hline \multicolumn{5}{|l|}{ Physical capital } \\
\hline Land & $0.102 * *$ & 0.034 & $0.104^{* *}$ & 0.034 \\
\hline Home & $0.064^{*}$ & 0.027 & $0.070^{*}$ & 0.027 \\
\hline Business & $-0.166^{* * *}$ & 0.039 & $-0.168^{* * *}$ & 0.039 \\
\hline \multicolumn{5}{|l|}{ Key control } \\
\hline \multicolumn{5}{|l|}{ Cost of migration } \\
\hline Natural log of distance & -0.055 & 0.037 & $0.349^{* * *}$ & 0.080 \\
\hline \multicolumn{5}{|l|}{ Interactions } \\
\hline Individual social capital $\times \log$ distance & - & - & $-0.218^{* * *}$ & 0.049 \\
\hline Prop. migrants $\times$ log distance & - & - & $-0.012^{* *}$ & 0.004 \\
\hline Individual human capital $\times \log$ distance & - & - & $-0.010^{*}$ & 0.004 \\
\hline \multicolumn{5}{|l|}{ Other controls } \\
\hline \multicolumn{5}{|l|}{ Community size } \\
\hline Metro area & $-0.460^{* * *}$ & 0.050 & $-0.440^{* * *}$ & 0.050 \\
\hline Town or city & - & - & - & - \\
\hline Rural village & $0.084^{* *}$ & 0.027 & $0.090^{* * *}$ & 0.027 \\
\hline \multicolumn{5}{|l|}{ Country of origin } \\
\hline Mexico & - & - & - & - \\
\hline Dominican republic & $-0.669^{* * *}$ & 0.178 & $-0.665^{* * *}$ & 0.178 \\
\hline Costa rica & $-0.239^{* *}$ & 0.090 & $-0.304^{* * *}$ & 0.091 \\
\hline Nicaragua & $-0.982^{* * *}$ & 0.178 & $-1.001^{* * *}$ & 0.178 \\
\hline Peru & 0.421 & 0.429 & 0.059 & 0.434 \\
\hline \multicolumn{5}{|l|}{ Demographic background } \\
\hline Age & $-0.051^{* * *}$ & 0.008 & $-0.050^{* * *}$ & 0.008 \\
\hline Age squared & -0.00001 & 0.000 & -0.00002 & 0.000 \\
\hline Married or in consensual union & $0.251^{* * *}$ & 0.036 & $0.250^{* * *}$ & 0.036 \\
\hline Number of children under 18 & 0.004 & 0.007 & 0.003 & 0.007 \\
\hline \multicolumn{5}{|l|}{ Period } \\
\hline Before 1980 & - & - & - & - \\
\hline 1980-1989 & $0.101^{* * *}$ & 0.030 & $0.104^{* * *}$ & 0.030 \\
\hline 1990-1995 & $-0.102^{* *}$ & 0.036 & $-0.105^{* *}$ & 0.036 \\
\hline After 1996 & $0.082+$ & 0.042 & $0.088^{*}$ & 0.042 \\
\hline Intercept & -0.176 & 0.320 & $-3.304^{* * *}$ & 0.634 \\
\hline Likelihood ratio & $25,289.31^{* * *}$ & & & \\
\hline Somer's D & 0.742 & & 0.743 & \\
\hline Person years & 76,275 & & 76,275 & \\
\hline
\end{tabular}


has a rather large positive effect on the likelihood of repeat migration. Thus, at the minimum observed distance, the swing in migration probabilities is from 0.11 to 0.06 as community social capital goes from minimum to maximum, whereas at the maximum observe distance the swing is from 0.03 to 0.43 . Being in a community with a large number of fellow migrants thus plays a much more important role in promoting repeat migration when it is far from the United States than when it is near.

Although the interaction between human capital and distance is significant statistically, coefficients associated with both the main effects and the interaction term are so small as to have no substantive effect. Human capital ends up having a marginal effect on the likelihood of repeat migration at all distances and is thus not plotted. Selection into the pool of repeat migrants is thus on the basis of social capital and migration specific human capital, with quite different patterns prevailing in countries at different distances from U.S. destinations. In particular, where the costs of migration are low, as in Mexico community social capital increases the odds of taking another trip, but when they are high, as in Peru, social capital reduces the odds of repeat migration.

\section{Conclusions}

In this analysis, we combined data from the Latin American Migration Project and the Mexican Migration Project to study the effects of different forms of capital on processes of international migration to the United States from Mexico, the Dominican Republic, Nicaragua, Costa Rica, and Peru. We estimated discrete-time event history models to predict the odds of taking first and subsequent trips to the United States in order to determine whether network connections and the social capital they yield operate similarly to promote migration across settings. We considered measures of both individual and community level social capital, measuring strong and weak ties, and specified several interactions to test specific hypotheses about how the effects of social capital vary under conditions of low versus high costs of migration and on first versus later trips.

We found that both individual social capital (measured by having ties to specific kinds of people with U.S. migratory experience) and community social capital (measured by the relative proportion of migrants in the community) indeed operate to promote and sustain international migration in different national settings across Latin America. The important role played by migrant networks in explaining the likelihood of leaving on first trips to the United States are not confined to Mexico, but occur in other migrantsending countries in the Western Hemisphere. Like other studies, we found that a rising prevalence of migrants in the community strongly increases the likelihood of outmigration of others, thus confirming a key pathway in the cumulative causation of migration. Among individual indicators of social capital, having a sibling with prior migrant experience has the strongest influence in predicting out-migration to the United States, with ties to parents, wives, and children having about half the effect of sibling ties. Nonetheless, the individual effects are all significant and, in general, the more connections one has to people with U.S. experience, the greater the odds of leaving on an initial U.S. trip, an effect strongly confirmed by the combined index of individual human capital we developed to estimate interactive models.

Despite the apparent universality of social capital effects across Latin America, however, the relative power of social capital in determining international migration is not uniform across settings. The size of individual social capital effects varies with the cost of migration, as measured by distance from U.S. destinations, and between first and later trips. Strong ties (direct connections to people with migrant experience) generally become more powerful in predicting first migration as distance increases, whereas weak ties (measured by the overall prevalence of migrants in the community) become less powerful in predicting migration as distance rises.

We also found that the decision calculus changes for first and later trips. In contemplating an initial trip, people do not have access to migration-specific human capital (knowledge and experience gained through migration itself) and rely heavily on social capital (weak and strong ties to people with U.S. experience) to support and sustain international movement. The effect of social capital in predicting later trips depends, however, on distance from U.S. destinations. In both cases, social capital is negatively related to the likelihood of taking an additional trip at long distances but positively related at short distances. Both weak and strong ties have progressively stronger and more positive effects in predicting additional trips as the cost of migration drops.

In addition to significant interactions between cost and social capital, we also found a strong interaction between cost and human capital (education, experience, and skill) in predicting first trips, such that the direction of human capital's effect was reversed when moving from short to long distances. At short distances where the cost of migration is low, the likelihood of taking a first U.S. trip is negatively related to human capital but at long distances with high cost it is positively related. Although the interaction between education and distance is also statistically significant in predicting later trips, in substantive terms the effect is trivial and migrants do not appear to be selected into a repeat migration on the basis of skill and education.

These findings underscore the importance of undertaking comparative analyses in trying to understand how social capital affects migration. Prior work has established many seemingly "hard" findings about how social capital works to promote international movement, but the research to date has been disproportionately on Mexico, which is inevitably a special case given its shared border with the United States. Our results suggest that even after controlling for social capital, human capital, and distance, the odds of taking first and later trips are greater when two countries share a border. Moreover, distance itself conditions the nature and direction of many effects, implying that certain seemingly hard findings based on research done in Mexico may reflect its unique circumstances rather than general processes. For example, whereas in Mexico the odds of taking an additional trip rise with each trip taken and each year of U.S. experience, 
the more general finding is that the likelihood of repeat migration rise with the number of trips but fall with total experience. Given its shared border, Mexico is unique in being able to sustain widespread recurrent migration, whereas migrants in other countries are compelled to adopt long-term settlement as the preferred strategy.

Likewise, although migrants in Mexico are well known to be negatively selected on the basis of human capital traits such as skills and education, our results suggest this pattern is at least in part explained by how human capital interacts with distance. On initial trips, in particular, the relationship between human capital and migration is negative at short distances (as in Mexico) but positive at long distances (as in Nicaragua, Costa Rica, and Peru). Similarly, research in Mexico has shown that community social capital-the proportion of migrants in the community-is powerful in predicting the likelihood of both initial and subsequent out-migration, but the interactions reveal that this effect is largely a result of Mexico's proximity to the United States, and that the positive effect of community social capital diminishes sharply as the cost of migration rises. In contrast, the strong effect individual social capital has in predicting first trips from Mexico is even stronger in other, more distant countries. In contrast, the strong effect of individual social capital in predicting additional trips among Mexicans is actually reversed and becomes negative among migrants from countries that are distant from the United States.

These analyses broaden the base of generalization for the theory of social capital and extend the applicability of migrant network effects to new settings. We have documented the existence of such networks and the importance of the social capital they yield in determining migration from a variety of different settings in the Americas and have shown how certain variations in context such as the relative cost of migration can amplify or reduce the basic migrationenhancing effects of social capital. As additional data from other countries become available through the Latin American Migration Project and newer projects ongoing in Poland, Africa, and China, we hope to continue to expand the basis for empirical and theoretical generalization.

\section{References}

[1] D. S. Massey, J. Arango, G. Hugo, A. Kouaouci, A. Pellegrino, and J. E. Taylor, Worlds in Motion: International Migration at the End of the Millennium, Oxford University Press, Oxford, UK, 1998.

[2] T. Mouw, "Estimating the causal effect of social capital: a review of recent research," Annual Review of Sociology, vol. 32, pp. 79-102, 2006.

[3] A. D. Bagchi, "Migrant networks and the immigrant professional: an analysis of weak ties," Population Research and Policy Review, vol. 20, no. 1-2, pp. 9-31, 2000.

[4] R. Klvaňová, "Moving through social networks: the case of Armenian migrants in the Czech Republic," International Migration, vol. 48, no. 2, pp. 103-132, 2010.

[5] S. K. Akcapar, "Re-Thinking migrants' networks and social capital: a case study of Iranians in Turkey," International Migration, vol. 48, no. 2, pp. 161-196, 2010.
[6] D. S. Massey, R. Alarcon, J. Durand, and H. Gonzalez, Return to Aztlan: The Social Process of International Migration from Western Mexico, University of California Press, Berkeley, Calif, USA, 1987.

[7] D. S. Massey and F. G. España, "The social process of international migration," Science, vol. 237, no. 4816, pp. 733738, 1987.

[8] D. S. Massey and K. E. Espinosa, "What's driving MexicoU.S. migration? A theoretical, empirical, and policy analysis," American Journal of Sociology, vol. 102, no. 4, pp. 939-999, 1997.

[9] K. E. Espinosa and D. S. Massey, "Undocumented migration and the quantity and quality of social capital," Soziale Welt, vol. 12, pp. 141-162, 1997.

[10] S. M. Kanaiaupuni, "Reframing the migration question: an analysis of men, women, and gender in Mexico," Social Forces, vol. 78, no. 4, pp. 1311-1347, 2000.

[11] M. Cerrutti and D. S. Massey, "On the auspices of female migration from Mexico to the United states," Demography, vol. 38, no. 2, pp. 187-200, 2001.

[12] S. R. Curran and E. Rivero-Fuentes, "Engendering migrant networks: the case of Mexican migration," Demography, vol. 40, no. 2, pp. 289-307, 2003.

[13] D. S. Massey, M. J. Fischer, and C. Capoferro, "Gender and international migration in Latin America," in Proceedings of the Annual Meeting of the American Sociological Association, San Francisco, Calif, USA, 2004.

[14] A. Palloni, D. S. Massey, M. Ceballos, K. Espinosa, and M. Spittel, "Social capital and international migration: a test using information on family networks," American Journal of Sociology, vol. 106, no. 5, pp. 1262-1298, 2001.

[15] K. Munshi, "Networks in the modern economy: Mexican migrants in the U. S. Labor market," Quarterly Journal of Economics, vol. 118, no. 2, pp. 549-599, 2003.

[16] D. S. Massey, L. Goldring, and J. Durand, "Continuities in transnational migration: an analysis of nineteen Mexican communities," American Journal of Sociology, vol. 99, no. 6, pp. 1492-1533, 1994.

[17] D. S. Massey and R. M. Zenteno, "The dynamics of mass migration," Proceedings of the National Academy of Sciences of the United States of America, vol. 96, no. 9, pp. 5328-5335, 1999.

[18] S. R. Curran, F. Garip, C. Chung, and K. Tangchonlatip, "Gendered migrant social capital: evidence from Thailand," Social Forces, vol. 84, no. 1, pp. 225-255, 2005.

[19] K. M. Donato, J. Hiskey, J. Durand, and D. S. Massey, "Migration in the Americas: Mexico and Latin America in comparative context," The Annals of the American Academy of Political and Social Science, vol. 630, no. 1, pp. 6-17, 2010.

[20] S. E. Alvarado and D. S. Massey, "In search of peace: structural adjustment, violence, and international migration," The Annals of the American Academy of Political and Social Science, vol. 630, no. 1, pp. 137-161, 2010.

[21] E. Fussell, "The cumulative causation of international migration in Latin America," The Annals of the American Academy of Political and Social Science, vol. 630, no. 1, pp. 164-177, 2010.

[22] A. Takenaka and K. A. Pren, "Determinants of emigration: comparing migrants' selectivity from Peru and Mexico," The Annals of the American Academy of Political and Social Science, vol. 630, no. 1, pp. 178-193, 2010.

[23] D. S. Massey and F. Riosmena, "Undocumented migration from Latin America in an era of rising U.S. enforcement," The Annals of the American Academy of Political and Social Science, vol. 630, no. 1, pp. 294-321, 2010. 
[24] T. D. Wilson, "Weak ties, strong ties: network principles in Mexican migration," Human Organization, vol. 57, no. 4, pp. 394-403, 1998.

[25] Aysa Maria, Dominican and Mexican Labor Migrants to the United States: Are they Alike?vol. 15 of Scientific Series on International Migration of Population: Russia and Contemporary World, Moscow State "Lomonosov" University, Moscow, Russia, 2005.

[26] F. Garip, Discovering Diverse Mechanisms of Migration: The Mexico-U.S. Stream from 1970 to 2000, Department of Sociology, Harvard University, 2010.

[27] F. Nadia, R. H. León, and D. S. Massey, "Social capital and emigration from rural and urban communities," in Crossing the Border: Research from the Mexican Migration Project, J. Durand and D. S. Massey, Eds., pp. 184-200, Russell Sage Foundation, New York, NY, USA, 2004.

[28] F. Nadia, "The interrelation between social context, social structure, and social capital of international migration flows from Mexico to the U.S.: the case of Guanajuato, Mexico," in Proceedings of the Annual Meeting of the Population Association of America, Philadelphia, Pa, USA, March 2005.

[29] E. Fussell and D. S. Massey, "The limits to cumulative causation: international migration from Mexican urban areas," Demography, vol. 41, no. 1, pp. 151-171, 2004.

[30] F. Garip and S. Curran, "Increasing migration, diverging communities: changing character of migrant streams in rural Thailand," Population Research and Policy Review, vol. 29, pp. 659-685, 2009.

[31] A. Singer, "The social process of undocumented border crossing among Mexican migrants," International Migration Review, vol. 32, no. 3, pp. 561-592, 1998.

[32] L. A. Sjaastad, "The costs and returns of human migration," Journal of Political Economy, vol. 70, pp. 80-93, 1992.

[33] M. P. Todaro, "A model of labor migration and urban unemployment in less-developed countries," The American Economic Review, vol. 59, pp. 138-148, 1969.

[34] J. J. Heckman and Y. Rubinstein, "The benefits of skill: the importance of noncognitive skills: lessons from the GED testing program," American Economic Review, vol. 91, no. 2, pp. 145-154, 2001.

[35] M. J. Pfeffer and P. A. Parra, "Strong ties, weak ties, and human capital: Latino immigrant employment outside the enclave," Rural Sociology, vol. 74, no. 2, pp. 241-269, 2009.

[36] J. E. Taylor, "Undocumented Mexico-US migration and the returns to households in rural Mexico," American Journal of Agricultural Economics, vol. 69, no. 3, pp. 626-638, 1987.

[37] S. Oded, The Migration of Labor, Basil Blackwell, Cambridge, UK, 1991.

[38] D. S. Massey, "The ethnosurvey in theory and practice," International Migration Review, vol. 21, no. 4, pp. 1498-1522, 1987.

[39] D. S. Massey and R. Zenteno, "A validation of the ethnosurvey: the case of Mexico-U.S. migration," International Migration Review, vol. 34, no. 3, pp. 766-793, 2000.

[40] D. S. Massey and C. Capoferro, "Measuring undocumented migration," International Migration Review, vol. 38, no. 3, pp. 1075-1102, 2004.

[41] D. Jorge and D. S. Massey, Crossing the Border: Research from the Mexican Migration Project, Russell Sage Foundation, New York, NY, USA, 2004.

[42] D. S. Massey and M. Sana, "Patterns of U.S. migration from Mexico, the Caribbean, and central America," Migraciones Internacionales, vol. 2, no. 2, pp. 1-39, 2004.
[43] F. Riosmena, "Policy shocks: on the legal auspices of Latin American migration to the United States," The Annals of the American Academy of Political and Social Science, vol. 630, no. 1, pp. 270-293, 2010.

[44] J. B. Martin, Overtaken by Events: From the Death of Trujillo to the Civil War, Doubleday, New York, NY, USA, 1966.

[45] D. S. Massey, J. S. Rugh, and K. A. Pren, "The geography of undocumented Mexican Migration," Mexican StudiesEstudios Mexicanos, vol. 26, no. 1, pp. 129-152, 2010.

[46] E. C. Norton, H. Wang, and C. Ai, "Computing interaction effects and standard errors in logit and probit models," The Stata Journal, vol. 4, no. 2, pp. 154-164, 2004.

[47] D. S. Massey, "The settlement process among Mexican migrants to the United States: new methods and findings," in Immigration Statistics: A Story of Neglect, pp. 255-292, National Academy Press, Washington, DC, USA, 1985.

[48] D. S. Massey, "The social organization of Mexican migration to the United States," The Annals of the American Academy of Political and Social Science, vol. 487, pp. 102-113, 1986. 


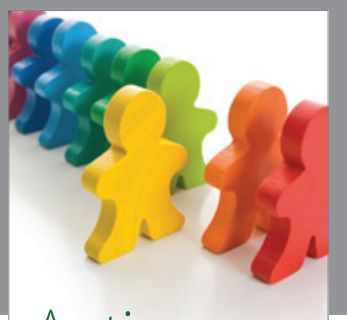

Autism

Research and Treatment
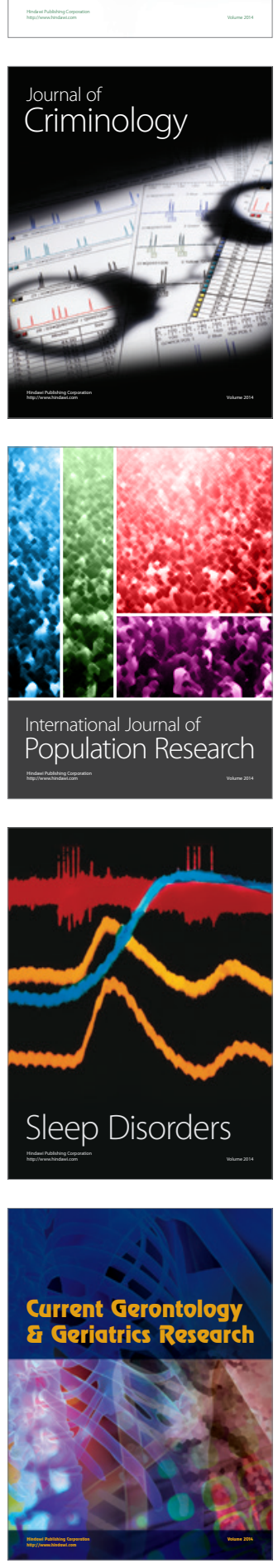
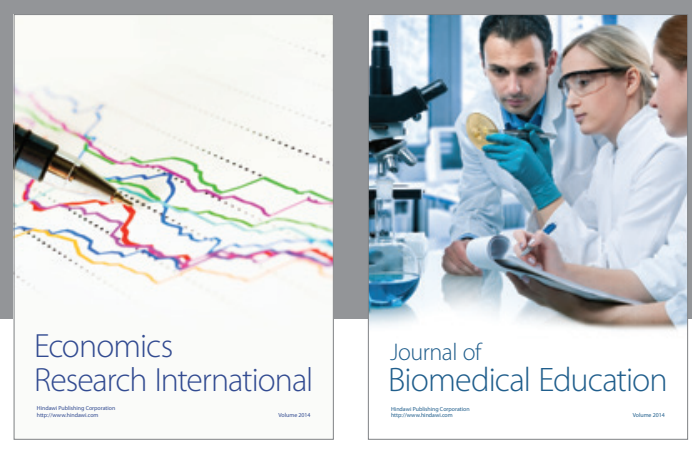

Journal of

Biomedical Education

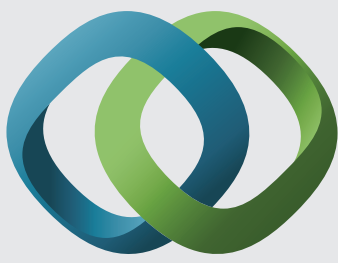

\section{Hindawi}

Submit your manuscripts at

http://www.hindawi.com
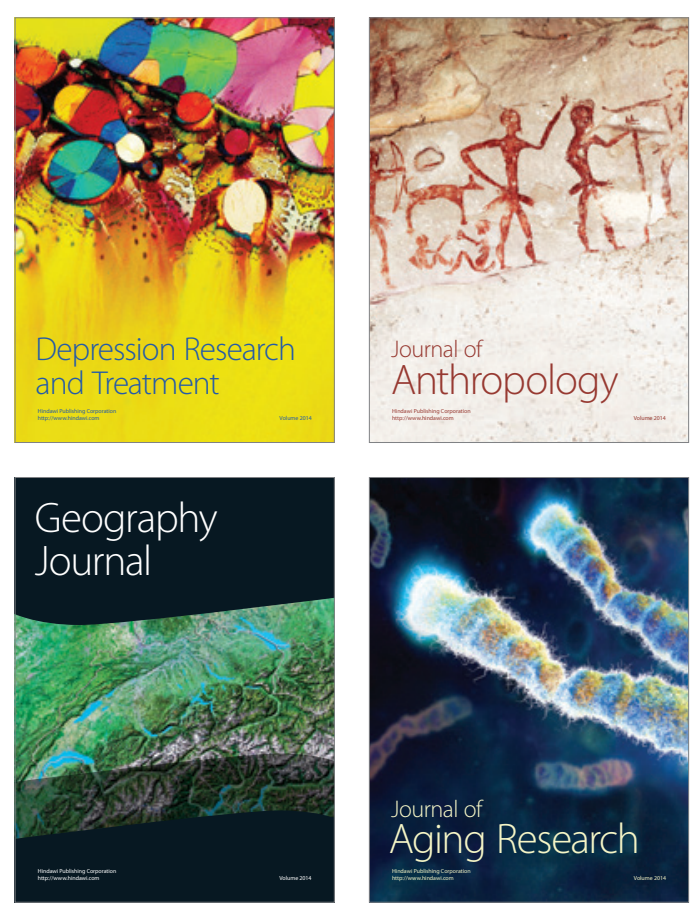

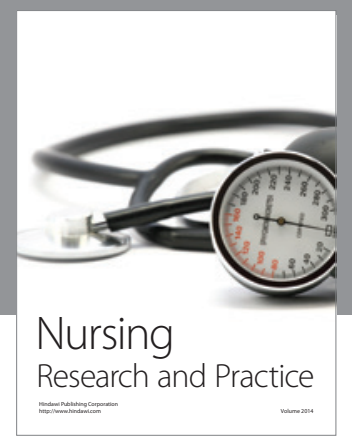

Nursing

Research and Practice

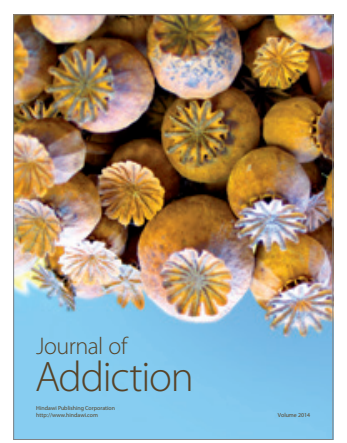

Child Development

Research

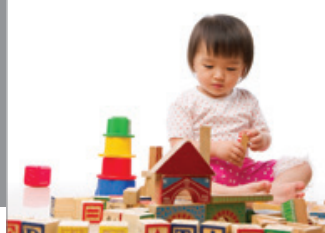

迥
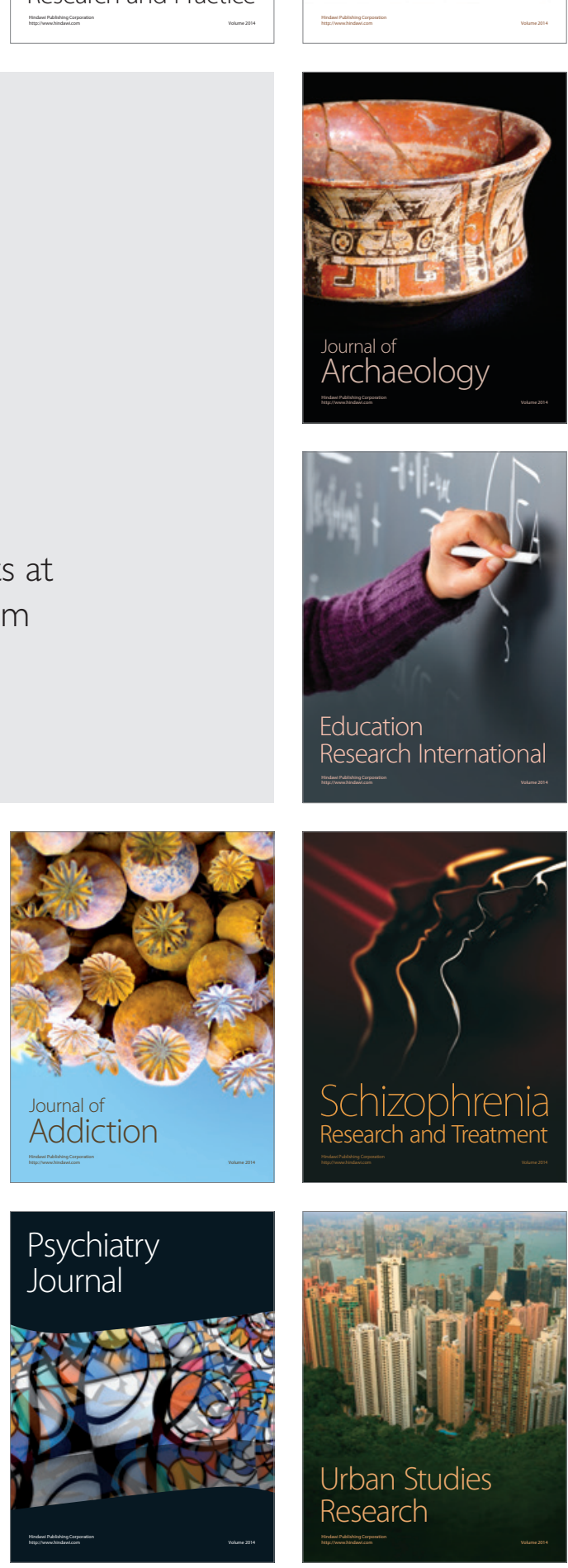